\title{
Cenários de Foresight Estratégico do setor de telecomunicações 5G: um espectro de oportunidades na Transformação Digital
}

Na era da Transformação Digital as tecnologias inovadoras geralmente alteram as proposições de valor estabelecidas e tornam inadequados os métodos tradicionais de planejamento estratégico. Neste artigo, apresentamos o uso da modelagem de negócios baseada em cenários para explorar o setor das redes de comunicação móvel $(5 \mathrm{G})$ de quinta geração. Discutimos quatro cenários que foram desenvolvidos em um esforço colaborativo entre diferentes perspectivas mercadológicas. Em seguida, descrevemos a abordagem de Foresight Estratégico que é um processo prospectivo de antecipação e construção de cenários para orientar a ação para construir a visão estratégica do futuro com apropriação, amplitude, profundidade e utilização técnicas e métodos, rigorosos e colaborativos. Essa abordagem complementa as técnicas tradicionais integrando mudanças multidimensionais, desde inovação tecnologia, regulação, dinamismo da cadeia de valor e evolução da proposição de valor. Conclui-se ainda que a contribuição e a abordagem para a construção da visão estratégica do futuro das organizações tecnológicas de $5 \mathrm{G}$, por meio do processo prospectivo e construção de cenários é particularmente valiosa em ambientes caracterizados por um alto nível de incerteza e complexidade.

Palavras-chave: 5g; Foresight Estratégico; Planejamento Estratégico; Modelagem de Negócios.

\section{Scenarios of Strategic Foresight in the $5 G$ telecommunications sector: a spectrum of opportunities in Digital Transformation}

\begin{abstract}
In the age of Digital Transformation, innovative technologies often changed as value propositions used and traditional methods of strategic planning become inadequate. In this article, we introduce the use of scenario-related business modeling to explore the fifth generation mobile communications (5G) networking industry. We discuss four scenarios that were developed in a collaborative effort between different marketing perspectives. Then, describing the Strategic Foresight approach, which is a forward-looking, scenario-building process to guide action to create a strategic vision of the future with rigorous, collaborative appropriation, breadth, depth, and technical use. This approach complements traditional techniques, integrating multidimensional changes from technological innovation, regulation, value chain dynamism, and value proposition evolution. Conclude further that a contribution and approach to building the strategic vision of the future of $5 \mathrm{G}$ technology applications through the prospective process and scenario building are particularly valuable in environments characterized by a high level of uncertainty and complexity.
\end{abstract}

Keywords: 5g; Strategic Foresight; Strategic planning; Business Modeling.

Topic: Marketing e Estratégias Mercadológicas

Reviewed anonymously in the process of blind peer.
Received: 19/12/2019

Approved: 29/01/2020
Norberto de Almeida Andrade (iD

Universidade Nove de Julho, Brasil

http://lattes.cnpq.br/5093838245289523

http://orcid.org/0000-0002-2048-0940

norberto.andrade@fatec.sp.gov.br

Giuliano Carlo Rainatto (ic)

Faculdades Metropolitanas Unidas, Brasil http://lattes.cnpq.br/8960268067561905 http://orcid.org/0000-0002-7205-4820

giulianorainatto@yahoo.com.br

Ricardo da Silva Santana

Faculdades Metropolitanas Unidas, Brasil http://lattes.cnpq.br/9533267322245694 http://orcid.org/0000-0002-3222-2172 santana_ric@hotmail.com

\author{
Fonttamara Leite Lima (iD) \\ Faculdades Metropolitanas Unidas, Brasil \\ http://lattes.cnpq.br/1062644214113711 \\ http://orcid.org/0000-0002-4084-5329 \\ mara.limaferreira@gmail.com \\ Mafalda Maria de Medeiros Anderson \\ Faculdades Metropolitanas Unidas, Brasil \\ http://lattes.cnpq.br/3684288458742735 \\ http://orcid.org/0000-0002-8644-4037 \\ mafalda.medeiros@terra.com.br
}

Referencing this:

ANDRADE, N. A.; RAINATTO, G. C.; SANTANA, R. S.; LIMA, F. L.; ANDERSON, M. M. M.. Cenários de Foresight Estratégico do setor de telecomunicações 5G: um espectro de oportunidades na Transformação Digital. Revista Brasileira de Administração Científica, v.11, n.1, p.205-223, 2020. DOI: http://doi.org/10.6008/CBPC2179$\underline{684 X .2020 .001 .0015}$ 


\section{INTRODUÇÃO}

Em todo o mundo, consumidores, operadoras de telecomunicações e clientes corporativos esperam ansiosamente as novas redes 5G. Para os consumidores, esse entusiasmo é motivado pelas perspectivas de conexões de banda larga móvel mais rápidas e acesso sem fio (AGIWAL et al., 2019). O setor de telecomunicações está em um estágio inicial no desenvolvimento da tecnologia 5G. Essa tecnologia disruptiva possui um valor econômico promissor que pode levar a uma sociedade 'hiperconectada', na qual os dispositivos móveis desempenharão um papel significativo na vida das pessoas (TRAN et al., 2017). Desde 2012, muitas iniciativas do governo, juntamente com investimentos de empresas de telecomunicações, moldaram o desenvolvimento do 5G. Fatores como o aumento da demanda em banda larga móvel, o crescente uso de smartphones e dispositivos inteligentes, com a crescente demanda de adoção de vídeo móvel, devem impulsionar o mercado 5 G durante o período previsto (PALATTELLA et al., 2016).

Atualmente, todo governo está entusiasmado em ficar à frente da curva no espaço 5G. Segundo o relatório 'Global 5 G Market (2019-2025)' os governos do Japão, Coréia do Sul, EUA e China também foram particularmente ativos no lançamento da tecnologia $5 \mathrm{G}$ até o final de 2019. Espera-se que o mercado global de 5 G atinja US $\$ 277$ bilhões em 2025 a um CAGR (Compound Annual Growth Rate) de 111\% durante 20192025. Com base nos tipos de conexão, o mercado pode ser classificado como conexões celulares SIM e conexões celulares M2M SIM. Até 2025, o número de conexões celulares SIM 4G será responsável por $57 \%$ do total de conexões, mas a conexão celular SIM 5 G terá a maior taxa de crescimento de $146 \%$ durante o período de previsão.

As políticas e projetos do governo, como o Programa Nacional 863 da China, o 13ㅇ Plano Quinquenal da China, o Projeto 5G Brasil, a Iniciativa Avançada de Pesquisa Sem Fio e a ENCQOR suportaram os requisitos de $P \& D$ e estão se esforçando para comercializar o 5 G até 2019. Até 2025, a América do Norte estará esperase que domine o mercado, gerando $45 \%$ da receita total de celulares de 5 G SIM, seguida pela Europa e ÁsiaPacífico (FREUND et al., 2019). A rede 5 G suportará inovações tecnológicas promissoras, incluindo a Internet das Coisas (IOT), robôs autônomos para o setor agrícola, Sistemas de Transporte Inteligentes (STI), redes inteligentes de utilidades, drones e muitos outros dispositivos conectados (BEGA et al., 2019).

Os dispositivos M2M de penetração para uso industrial aumentarão e se estima que haverá cerca de meio bilhão de conexões M2M em setores como varejo, manufatura e energia até 2025. Isso será amplamente impulsionado pela automação e inteligência artificial (IA). Assim, espera-se que as conexões celulares globais 5G SIM M2M se expandam a um CAGR de 231\%. Em 2025, espera-se que a Europa domine o mercado, gerando 35\% da receita total de celulares 5G SIM M2M, seguida pela Ásia-Pacífico e América do Norte (FREUND et al., 2019).

Com base nas regiões, o mercado é segmentado para a América do Norte, Europa, Ásia-Pacífico, América Latina, Oriente Médio e África. A América do Norte terá a maior participação de mercado de $44 \%$ até 2025. A maioria do consumo de dados ocorrerá através do uso de vídeo. Durante 2019-2023, o tráfego de vídeo aumentará de 82 EB/ano para 731 EB/ano, com um CAGR de 55\% (AGIWAL et al., 2019). As empresas 
de mídia desenvolverão estratégias e planos de negócios para gerar receita com essa tendência. A região Ásia-Pacífico será responsável pelo maior número de assinantes de celular 5 G até 2025 . Embora o crescimento da receita tenha diminuído nos últimos tempos, espera-se que esta região mostre comprometimento positivo em termos da rápida adoção da loT no futuro próximo (FREUND et al., 2019). No lado corporativo, as operadoras e os clientes estão entusiasmados com as possibilidades de novos modelos comerciais habilitados pela capacidade de divisão de rede da $5 \mathrm{G}$ e uma ampla variedade de novos casos de uso suportados por baixa latência da rede e consumo de energia (PALATTELLA et al., 2016).

Diferentemente das tecnologias de comunicação anteriores, o $5 \mathrm{G}$ deve, em primeiro lugar, acomodar as necessidades de vários setores e mercados verticais além do mercado consumidor. O $5 \mathrm{G}$ está posicionado para ser um componente importante da transformação digital corporativa e pode se tornar uma plataforma de comunicação sem fio confiável para simplificar os processos operacionais (TRAN et al., 2017).

Quando isso acontece, o $5 \mathrm{G}$ ajudará a criar novas oportunidades de negócios, caso contrário não é possível com as tecnologias atuais e estimulará um novo ecossistema de desenvolvedores B2B focado em casos de uso corporativos. O $5 \mathrm{G}$ foi projetado para criar trilhões de valor econômico em muitos setores verticais da empresa. Para acompanhar essas promessas, o setor de telecomunicações deve revisar as atuais estratégias de implementação $5 G$ e se concentrar além da maior capacidade de rede e menor latência (AGIWAL et al., 2019).

Embora a proposta de valor das implementações iniciais do 5 G se encaixe no objetivo e no caso de negócios do mercado consumidor, elas estão longe de serem otimizadas para desbloquear oportunidades de negócios muito maiores nas verticais das empresas, onde o $5 \mathrm{G}$ poderia ser usado como uma ferramenta essencial para acelerar sua transformação digital (BEGA et al., 2019). A flexibilidade na implementação da rede, a interoperabilidade com os processos de operação herdados, a relação custo-benefício, o determinismo da rede, a segurança e a confiabilidade serão igualmente importantes para a empresa, pois melhoram o desempenho da rede (PALATTELLA et al., 2016).

De fato, o $5 \mathrm{G}$ é mais do que apenas uma evolução da tecnologia de acesso ao LTE (um sistema OFDMA (Orthogonal Frequency Division Multiple Access) para espectro de banda larga, projetada para estender a capacidade da rede e diminuir sua latência (BEGA et al., 2019). O 5G deve ser percebido como uma ferramenta de transformação capaz de suportar implementações flexíveis e exigir mudanças arquiteturais radicais, por exemplo, colaboração entre espectro licenciado e não licenciado, suporte de redes públicas e privadas, suporte de vários serviços com diferentes requisitos sob demanda e trazer inteligência para a borda da rede para melhores experiências do usuário final (AGIWAL et al., 2019).

O 5G - quando atingir massa crítica nas verticais das empresas - transformará a cadeia de suprimentos de telecomunicações lineares e as parcerias serão vitais para o sucesso nesta nova era. O 5 G atuará como uma plataforma na qual os desenvolvedores criarão novos aplicativos corporativos B2B e o papel dos provedores de serviços móveis evoluirá do modelo como o conhecemos hoje, basicamente focado na conectividade, para aquele em que o $5 \mathrm{G}$ está posicionado como uma ferramenta fundamental para a indústria transformação digital (FREUND et al., 2019). A computação de bordo, o fatiamento de rede, as APIs 
(Application Programming Interface) e o surgimento de novos tipos de dispositivos - mesmo nas redes de provedores de serviços móveis - serão os principais componentes para os futuros negócios da empresa 5G (TRAN et al., 2017).

\section{REVISÃO TEÓRICA}

\section{Principais desafios de implementação}

Os implementadores de tecnologia nas verticais corporativas estão atualmente elaborando suas estratégias de transformação digital, onde a conectividade sem fio é um componente importante. Compreender as tecnologias sem fio não é a principal prioridade da maioria das empresas, muitas das quais são suportadas por tecnologias proprietárias (AGIWAL et al., 2019).

O 5G, por outro lado, tem como objetivo oferecer recursos de conectividade sem fio de nível de operadora, baixo custo e padrões a muitas verticais empresariais (FREUND et al., 2019). No entanto, a implementação de redes $5 \mathrm{G}$ cruza várias verticais e as indústrias enfrentarão alguns grandes desafios, os mais notáveis conforme Bega et al. (2019) são: Cada vertical da empresa representa um conjunto exclusivo de requisitos da $5 \mathrm{G}$ e pode haver diferenças significativas mesmo dentro da mesma vertical. $\mathrm{A}$ acomodação de todos esses requisitos em uma única infraestrutura mostra-se desafiadora e requer uma maneira meticulosa de como os recursos de rede são virtualizados em fatias e orquestrados; 0 setor de telecomunicações está adotando uma abordagem gradual para atualizar a rede de $4 \mathrm{G}$ para $5 \mathrm{G}$, começando por abordar as oportunidades de curto prazo que são predominantemente impulsionadas pelo mercado consumidor. $\mathrm{O}$ setor deve adotar uma abordagem mais equilibrada, porém radical, para implementar redes 5G, por exemplo, abordando o mercado corporativo que será a principal vaca leiteira a longo prazo. Atualizar a capacidade da rede, aprimorar a largura de banda do uso final ou a latência da rede não é suficiente para criar uma proposta de valor real para o mercado corporativo; Os órgãos reguladores e de padrão das telecomunicações estão focados em melhorar a experiência do consumidor e correm um sério risco de perder o curto espaço de tempo em que podem posicionar o $5 \mathrm{G}$ como uma ferramenta transformacional que visa o mercado corporativo. Há uma enorme lacuna entre os requisitos verticais da empresa e a visão da cadeia de suprimentos de telecomunicações para redes $5 \mathrm{G}$, muitas vezes com base na construção que elas virão. Se essa lacuna não for diminuída, o $5 \mathrm{G}$ continuará sendo uma tecnologia direcionada ao consumidor, cujas receitas não poderão justificar implantações em todo o país; As empresas de telecomunicações enfrentarão uma pressão crescente das empresas de Webscale que estão cada vez mais mirando as mesmas verticais que o mercado de telecomunicações $5 \mathrm{G}$ espera transformar 5 . Muitas empresas podem sequestrar as tecnologias $5 \mathrm{G}$ para construir suas próprias redes sob medida para seus próprios requisitos, o que pode levar a oportunidades perdidas. Pelos prestadores de serviços móveis existentes; Várias tecnologias 5G principais ainda não estão maduras e suas implementações podem exigir abordagens diferentes, dependendo da natureza dos mercados abordados. Esse desenvolvimento pode levar a uma potencial fragmentação da tecnologia se os implementadores não forem aceitos como principais influenciadores na 
evolução dos padrões $5 G$.

\section{Cenários de Foresight Estratégico para modelagem de negócios}

Muitas organizações viram uma mudança de uma economia impulsionada pela indústria para a economia baseada no conhecimento, o que levou a um aumento acentuado da incerteza e complexidade ambientais. Além disso, a ciência e a tecnologia se tornaram os principais impulsionadores de mudanças rápidas, complexas e generalizadas (ROHRBECK et al., 2018).

Consequentemente, explorar novos campos de negócios ou desenvolver novos produtos tornou-se cada vez mais desafiador e novas abordagens adequadas nesses ambientes são necessárias para a formação de estratégias e o gerenciamento de inovação em perspectiva (PIETROBELLI et al., 2016). A redução dos ciclos de vida do produto levou à necessidade de desenvolver métodos que permitam antecipar mudanças sistemáticas e traduzi-las em respostas organizacionais no campo do gerenciamento estratégico e de inovação (DING et al., 2017; JAUCH et al., 1986).

Explorar novos campos de negócios é uma tarefa desafiadora, pois requer a integração de várias perspectivas interdependentes, incluindo satisfação do cliente, potencial tecnológico, reação do concorrente, bem como envolvimento ativo das partes interessadas (MAHONEY et al., 1992). Além disso, o desenvolvimento de um novo campo de negócios ocorre quando um hiato entre as competências atuais e a concorrência futura é realizado e resolvido.

A inter-relação dinâmica entre competências tecnológicas e estratégia indica que a visão estratégica de uma empresa também deve ser dinâmica (VENKATRAMAN et al., 1984). Como resultado, a descontinuidade tecnológica deve ser explorada para evitar choques futuros, e a previsão é uma maneira de aproveitar as oportunidades, detectar e lidar com os problemas, além de ajudar a criar uma resposta oportuna às interrupções (DOKTOR et al., 1991). O planejamento de cenários, em particular, permite a antecipação de um futuro menos previsível, que é uma das principais características de eventos raros e impactantes, como a rápida difusão de inovações radicais (GOKHBERG et al., 2016).

\section{Planejamento de cenários e aprendizado organizacional}

O planejamento de cenários cresceu suas raízes no final da década de 1940, quando Herman Kahn discutiu o conceito de 'pensar o impensável'. Integrar as análises abrangentes à imaginação leva à criação de histórias orientadas para o futuro, denominadas "cenários" (MAHONEY et al., 1992). A investigação de como as organizações aprendem penetrou na academia no final dos anos 50 (DOKTOR et al., 1991). $O$ aprendizado organizacional foi definido como um processo de alteração de modelos mentais (ou seja, representações e suposições sobre como o mundo funciona) e processos, além de melhorar o desempenho da organização (DAl et al., 2015).

Argumenta-se que o aprendizado surgirá quando o conhecimento for transformado em comportamento recorrente e quando os modelos mentais e as experiências do mundo se adaptarem e se integrarem mutuamente (DING et al., 2017). O processo de pensamento de cenário promove o ciclo de 
aprendizado organizacional, onde o compartilhamento de ideias sobre as tendências emergentes, a construção de consenso, o planejamento e a atuação ocorrem coletivamente. A aprendizagem em loop duplo, que é o resultado de um modelo mental organizacional compartilhado, cria oportunidades e fornece soluções em potencial ao reformular o problema enfrentado em um desenvolvimento descontínuo (HINES et al., 2017). O planejamento de cenários envolve mapear modelos mentais, questionar modelos mentais (ou seja, normas e suposições) e aprimorar modelos mentais (LEAL et al., 2016). Através da causalidade, os velhos modelos mentais e a nova realidade se integrarão e criarão uma nova teoria que pode ser testada e desenvolvida refletindo sobre as consequências da ação (TSUI, 2007).

O planejamento de cenários permite repensar a realidade e leva a um aprendizado novo e experimental (DOKTOR et al., 1991). Usando o método do Cenário Estratégico Híbrido Futuro de Alfabetização, Hines et al. (2017) identificaram que dois tipos de aprendizado serão estabelecidos através do processo de pensamento de cenário: (1) criação de sentido (isto é, gerar significados compartilhados e explícitos) e (2) antecipação (isto é, entender a teoria e a prática da previsão).

Darkow (2015) diferenciava entre a aprendizagem no nível individual (isto é, 'atitudes de previsão') que está no domínio cognitivo e a aprendizagem no nível organizacional (isto é, 'atividade de previsão') que demonstra o tipo interativo e participativo de aprendizagem dentro das organizações. Com base nessa relação teórica e características e objetivos compartilhados, concluímos que um dos valores fundamentais do planejamento/pensamento de cenário está gerando um aprendizado organizacional profundo e eficiente.

\section{Ecossistemas de negócios e conceitos de modelo de negócios}

Ao discutir ecossistemas, diferentes tipos de ecossistemas podem ser identificados: negócios biológicos, industriais, sociais e digitais (ROHRBECK et al., 2018). Mahoney et al. (1992) introduziram ecossistemas de negócios orgânicos, concentrando-se em estratégias e relacionamentos de negócios. Carpenter (2002) afirmou que existem paralelos com negócios e ecossistemas naturais em que ambos são parcialmente intencionalmente formados e são parcialmente resultado de emergências acidentais, e são caracterizados por alta complexidade, interdependência, cooperação, competição e coevolução em busca de novas inovações.

Nesses ambientes, é essencial integrar a análise dos fatores de mudança com o mapeamento de participantes do mercado novos e existentes. Como um campo emergente, os modelos de negócios $5 \mathrm{G}$ foram discutidos apenas em uma extensão limitada na literatura. Rohrbeck et al. (2018) discutiram o modelo de negócios assistido por nuvem; Noll e Chowdhury introduziram modelos de negócios colaborativos e Rasheed, Rodriguez, Kibilda, Piesiewicz, Verikoukis, Gregorio, Gregorio e Moreira aplicaram o modelo de negócios de corretagem no contexto 5G.

No entanto, os estudos existentes não descrevem especificamente o impacto de cenários futuros alternativos para o 5G. Portanto, são necessárias mais pesquisas sobre os possíveis modelos de negócios no 5G, quando estamos nos aproximando de sua comercialização. Modelos de negócios são ferramentas incorporadas e que podem ser formadas contextualmente pela inovação tecnológica (GOKHBERG et al., 
2016). Um 'modelo de negócio', como mecanismo de planejamento e implementação de estratégia, permite a consideração de várias opções em um ambiente incerto e em rápida mudança. Na abordagem orientada à descoberta dos modelos de negócios, que visa detectar e explorar novos modelos, o papel do aprendizado e da experimentação é significativamente poderoso (LEAL et al., 2016).

Em um ambiente complexo e turbulento, as estratégias exigem perspicácia e experimentação instantânea e aprendizado evolutivo para serem eficazes (DAl et al., 2015). Por exemplo, Ding et al. (2017) discutiram a visão, a estratégia, a prática e a avaliação como processos de aprendizado paralelos relacionados ao aprendizado na criação e transformação de modelos de negócios. Portanto, os modelos de negócios que são capacitados pelo aprendizado podem ser considerados com potencial de serem mais sustentáveis e eficazes.

A noção de uso de um modelo de negócios como criação de valor (por exemplo, proposição de valor; por exemplo, inovação de produto) e construção de captura de valor (por exemplo, potencial de lucro, lógica/modelo de receita) foi abordada na maioria da literatura relacionada (ROHRBECK et al., 2018). O modelo 4C (ou seja, conexão, conteúdo, contexto e comércio) (Figura 1) como uma taxonomia de modelos de negócios foi apresentado por (TSUI, 2007) e ajuda a esclarecer os processos de criação e captura de valor na Web 2.0 contexto. Rohrbeck et al. (2018) estenderam a taxonomia ao contexto 5G e viram os quatro modelos de negócios como uma construção em camadas. As camadas superiores estão sendo suportadas e ativadas pelas camadas inferiores.

Segundo Palattella et al. (2016) da perspectiva de uma empresa individual, o modelo 4C pode ser praticado em uma ou em qualquer combinação de camadas. Da perspectiva ecossistêmica, as quatro camadas ajudam a formar uma lógica coerente de como diferentes negócios em um ecossistema estão interrelacionados (consulte a seção 4 para obter uma explicação detalhada do modelo).

Fornecer uma plataforma de comércio B2B, B2C, B2G, C2C, C2B, C2G, G2B, G2G, G2C

Fornecer serviços baseados em informações de contexto Em relação a usuários, equipamentos, perfil do sistema, localização

Fornecer conteúdo gerado pelo usuário, de propriedade de terceiros

Fornecer conexão com infraestrutura

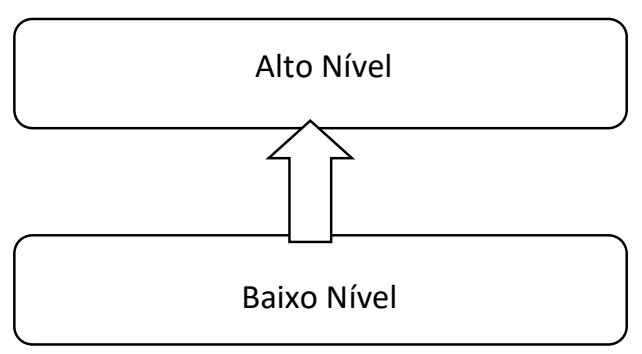

Figura 1: O Modelo de Negócios 4C no contexto 5G, modificado de Palattella et al. (2016).

\section{METODOLOGIA}

\section{Estratégia de pesquisa: propondo e aplicando uma nova abordagem}

Nesta pesquisa, testou-se uma nova metodologia para explorar novos campos de negócios que são complexos e incertos e relatou-se seus benefícios. A estrutura norteadora de nossa abordagem é o método de aprendizagem por ação antecipatória (Anticipatory Action Learning AAL), que tenta facilitar a aprendizagem em um sistema social.

AAL é um processo de visão democrática que conecta investigação, antecipação e aprendizado com 
ação, avaliação e tomada de decisão (DARKOW, 2015). O método visa fazer com que vários níveis de entendimento se mesclem aberta e progressivamente durante o processo. A AAL destaca o ajuste recíproco pluralista dos exercícios prospectivos e reflete a exploração de futuros alternativos (PIETROBELLI et al., 2016). Tanto a pesquisa-ação quanto o aprendizado-ação sublinham a necessidade de experimentar, refletir e aprender (CARPENTER, 2002). A abordagem participativa é benéfica para os workshops visionários criarem ideias inovadoras por meio de modelos conceituais (ou seja, procedimentos intelectuais estruturados). Sensemaking (Figura 2) por meio da reflexão e da análise das consequências de uma ação leva à melhoria do aprendizado individual e coletivo (DAl et al., 2015).

Com relação à função de ação do processo de cenário, o pensamento de cenário capacita a organização a aplicar seu entendimento na prática e reduz o efeito obstrutivo da fragmentação mental e de modelos incoerentes. Além disso, associa os futuros possíveis ao ambiente contextual existente e seu subsequente impacto na organização (MAHONEY et al., 1992).

Em consequência, espera-se que o método AAL forneça aos estrategistas insights sobre futuros plausíveis e seja útil no planejamento, tomada de decisões e, eventualmente, na modelagem do futuro. Essa exploração do futuro é crucial para criar uma plataforma de antecipação (isto é, preparar uma ou mais organizações para desenvolver um mercado futuro), (HINES et al., 2017). Mais especificamente, espera-se que o uso das informações de planejamento do cenário para acionar a geração de modelos de negócios desencadeie a inovação do modelo de negócios e estabeleça as bases para novos ecossistemas de negócios segundo Tsui (2007).

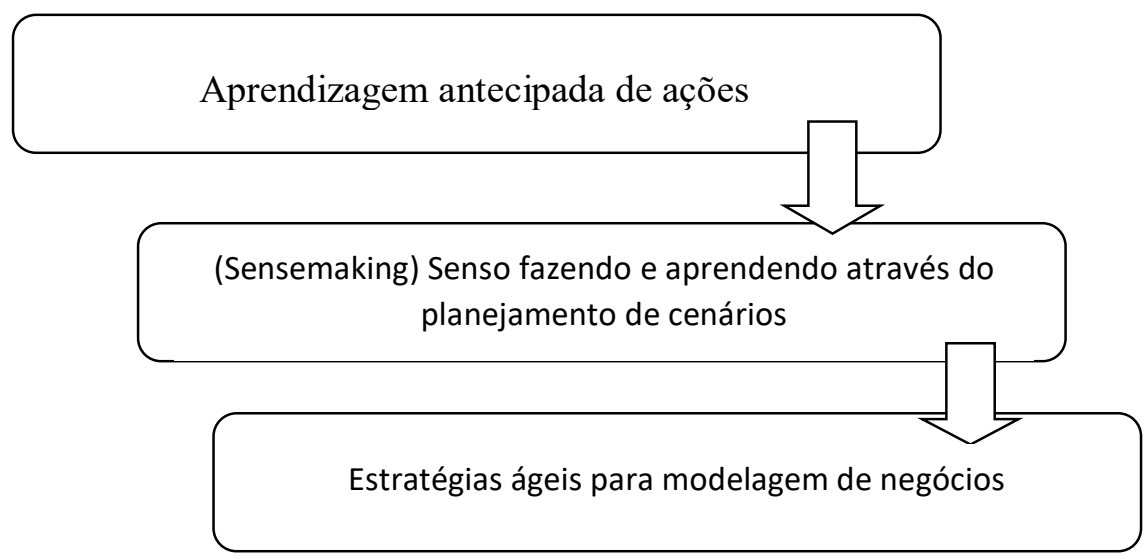

Figura 2: O processo de pesquisa conforme Tsui (2007).

Como primeira etapa, usou-se o workshop de planejamento de cenários que reuniu diferentes especialistas para discutir diferentes perspectivas relacionadas ao contexto do $5 G$, sob as perspectivas de tecnologia, negócios e regulamentação. Selecionamos os participantes por meio de uma entrevista para garantir um conjunto abrangente de conhecimentos e experiências relevantes (BEGA et al., 2019). Os participantes foram recrutados de diferentes participantes da rede de valor do ecossistema de comunicações sem fio (consulte a Tabela 1). Os 18 participantes foram organizados em quatro grupos que consistiam em organizações acadêmicas e empresas. 
Tabela 1: Participantes do projeto e composição do grupo de trabalho.

\begin{tabular}{|l|l|l|l|l|}
\hline Grupos & A & B & C & D \\
\hline $\begin{array}{l}\text { Empresas } \\
\text { Participantes }\end{array}$ & Huawei & CWC & IT Fórum 365 & Ericsson \\
\hline & Ericsson & Bittium & INATEL & INATEL \\
\hline & Nokia & IT Fórum 365(2) & Qualcomm & ANATEL(3) \\
\hline & INATEL & Nokia & Nokia & Nokia \\
\hline & Qualcomm & & & \\
\hline & $(1) \quad$ Instituto Nacional de Telecomunicações & & & \\
\hline & $(2) \quad$ Plataforma social B2B & & & \\
\hline & $(3) \quad$ Agência Nacional de Telecomunicações & & & \\
\hline
\end{tabular}

Os participantes foram orientados a criar quatro cenários futuros alternativos e plausíveis para o desenvolvimento de mercados $5 \mathrm{G}$. O processo do cenário foi exploratório, com o objetivo de aprender, despertar a consciência, inspirar a criatividade e examinar a interação social. Os cenários foram definidos em um período de três a cinco anos, incorporado ao setor de telecomunicações móveis que muda rapidamente (FREUND et al., 2019).

\section{RESULTADOS E DISCUSSÃO}

\section{Abordagem e processo de planejamento de cenários}

Nossa abordagem ao planejamento de cenários é prospectiva. Devido ao contexto e princípio do problema com o qual estamos lidando, não é possível considerar apenas uma dimensão para entendê-la e analisá-la. Portanto, é necessária uma abordagem multidisciplinar do pensamento sistêmico e da análise sistêmica para capturar a totalidade da realidade com todas as suas variáveis e suas inter-relações, independentemente do seu tipo (GOKHBERG et al., 2016).

A integração do pensamento sistêmico e do planejamento de cenários gera cenários plausíveis, pois a relação causal entre os fatores pode ser exibida (CARPENTER, 2002). Para o planejamento do processo, aplicamos a abordagem normalmente usada por Leal et al. (2016) e Rohrbeck et al. (2018) e consiste em seis etapas. No ponto de partida, o caso do cenário foi criado; os participantes obtiveram entendimento sobre os objetivos e o horizonte temporal dos cenários (etapa 1: abordando o tópico e o horizonte temporal). 0 objetivo foi explorar o tipo de impacto que o $5 \mathrm{G}$ poderia ter sobre as partes interessadas do ecossistema de negócios sem fio nos próximos 3-5 anos, criando cenários de negócios futuros alternativos. Então, começouse a questionar o presente para identificar as tendências, variáveis e fatores de mudança que moldarão o futuro do tópico do cenário (BEGA et al., 2019).

Em seguida, selecionou-se as variáveis críticas entre aquelas que tiveram grande impacto e baixa previsibilidade ou consequências desconhecidas na questão focal, pois são as forças motrizes que levam à ruptura (etapa 2: determinação de incertezas críticas), (DING et al., 2017). Em seguida, analisou-se o relacionamento e a interconectividade das variáveis para formular os possíveis resultados do desenvolvimento (etapa 3: criação de alternativas). Depois disso, usando uma matriz de impacto cruzado, alinhou-se as variáveis e estudou-se a existência e a força de seus elos causais. Identificou-se as possíveis extremidades alternativas (ou seja, projeção) dos temas criados (ou seja, drivers) para criar um sistema para navegar no futuro do tópico do cenário (etapa 4: calibrar uma futura bússola), (HINES et al., 2017). A Tabela 
2 mostra as quatro matrizes de cenário distintas que foram construídas com base nas variáveis identificadas e nos recursos genéricos previstos do futuro setor de telecomunicações. Os eixos vertical e horizontal de uma matriz de cenário denotam as dimensões e cada dimensão inclui duas extremidades que caracterizam as abordagens alternativas dentro dessa dimensão. As dimensões foram avaliadas como independentes uma da outra (ROHRBECK et al., 2018).

Tabela 2: Quatro matrizes de cenário e seus blocos de construção.

\begin{tabular}{|c|c|c|c|c|}
\hline $\begin{array}{l}\text { Eixos } \\
\text { matriciais }\end{array}$ & & Final 1 & Dimensões & Final 2 \\
\hline \multirow{2}{*}{$\begin{array}{l}\text { Matriz de } \\
\text { Cenário } 1\end{array}$} & Eixo Vertical & $\begin{array}{l}\text { Capacidade de criação. Qualidade de } \\
\text { Experiência (QoE) }\end{array}$ & Experiência do Usuário & $\begin{array}{l}\text { Nenhuma QoE é } \\
\text { necessária/esperada }\end{array}$ \\
\hline & $\begin{array}{l}\text { Eixo } \\
\text { Horizontal }\end{array}$ & Um jogador definido & $\begin{array}{l}\text { Seleção de canal de } \\
\text { distribuição }\end{array}$ & $\begin{array}{l}\text { Todos os jogadores podem } \\
\text { definir }\end{array}$ \\
\hline \multirow{2}{*}{$\begin{array}{l}\text { Matriz de } \\
\text { Cenário } 2\end{array}$} & Eixo Vertical & Requisitos definidos horizontalmente & Tecnologia & $\begin{array}{l}\text { Requisitos definidos } \\
\text { verticalmente }\end{array}$ \\
\hline & $\begin{array}{l}\text { Eixo } \\
\text { Horizontal }\end{array}$ & Estático & Função do operador & Dinâmico \\
\hline \multirow{2}{*}{$\begin{array}{l}\text { Matriz de } \\
\text { Cenário } 3\end{array}$} & Eixo Vertical & Streaming (entretenimento) & $\begin{array}{l}\text { Unidade de } \\
\text { desenvolvimento }\end{array}$ & $\begin{array}{l}\text { Internet das Coisas (IOT) } \\
\text { (utilitário) }\end{array}$ \\
\hline & $\begin{array}{l}\text { Eixo } \\
\text { Horizontal }\end{array}$ & Operador atual & $\begin{array}{l}\text { Modo de negócios do } \\
\text { operador }\end{array}$ & $\begin{array}{l}\text { Modelo } \\
\text { operador de pequenas } \\
\text { células }\end{array}$ \\
\hline \multirow{2}{*}{$\begin{array}{l}\text { Matriz de } \\
\text { Cenário } 4\end{array}$} & Eixo Vertical & Compartilhado & Papel dos recursos & Próprio \\
\hline & $\begin{array}{l}\text { Eixo } \\
\text { Horizontal }\end{array}$ & Centralizado & $\begin{array}{l}\text { Provisionamento de } \\
\text { serviços }\end{array}$ & Local \\
\hline
\end{tabular}

As dimensões foram selecionadas com base na lógica do ecossistema e como os recursos são oferecidos e distribuídos no ecossistema de negócios móveis. Ao todo, dezesseis cenários foram criados com base em quatro matrizes de cenário; cada um com duas dimensões distintas (ROHRBECK et al., 2018). No entanto, para reduzir o número de cenários e criar uma matriz de cenário genérica e mais coerente, mesclamos e integramos essas dimensões (ou seja, os eixos das matrizes), bem como os pontos finais das dimensões que eram tematicamente e semanticamente semelhantes a entre si. Por exemplo, as dimensões horizontais, como a seleção do canal de distribuição, o papel do operador, o modelo de negócios do operador e o fornecimento de serviços, estão todos relacionados ao tema 'operador'; portanto, os cenários criados com base nessas dimensões são semanticamente próximos e possuem características comuns (PIETROBELLI et al., 2016).

Na mesma linha, as dimensões verticais, incluindo experiência do usuário, tecnologia, unidade de desenvolvimento e o papel dos recursos, estão relacionadas ao tema 'conteúdo, ou seja, recursos'. Além disso, após examinar as características e o valor de todos os cenários criados nos eixos vertical e horizontal, percebeu-se que os eixos horizontais são sobre mercado dinâmico e estático e os eixos verticais são sobre compartilhamento e controle de recursos. Por exemplo, criando QoE, soluções tecnológicas horizontais e streaming não são viáveis sem o compartilhamento amplo de recursos no ecossistema de negócios móveis (DING et al., 2017).

Além disso, com a participação democrática de todos os jogadores na criação das regras do jogo, não é possível o surgimento de operadores locais de pequenas células e a prestação de serviços locais sem que o mercado seja aberto para atuar dinamicamente no ecossistema (GOKHBERG et al., 2016). A mesma 
justificativa indica que quando apenas um participante dominante define as regras, se a situação atual continuar sem mudanças no futuro e os serviços forem oferecidos apenas de forma centralizada, o mercado permanecerá estático (CARPENTER, 2002). De maneira semelhante, a falta de QoE exigida pelos clientes, soluções tecnológicas específicas verticais, utilizando a tecnologia da loT e mantendo os recursos individualmente refletem a atitude de controle dos participantes sobre seus recursos e as estruturas fixas do ecossistema. Assim, poderíamos mesclar os cenários e criar uma matriz de cenários (Figura 3), (TSUI, 2007).

Na próxima etapa, os cenários foram escritos com o objetivo de serem consistentes internamente, envolvendo lógica de causa-efeito, sendo relevantes para as questões de preocupação do participante e fornecendo ideias desafiadoras (DARKOW, 2015). As histórias de cenários representam quatro futuros alternativos e seus diferentes resultados (etapa 5: redigindo narrativas de cenário para cada quadrante). Finalmente, os participantes foram solicitados a se comunicar e refletir sobre os cenários desenvolvidos com base em sua plausibilidade, pertinência e implicação (etapa 6: refletir sobre o resultado final). Como segunda fase, realizou-se um workshop de modelagem de negócios em que o objetivo era explorar futuros modelos de negócios baseados em valor 5G para os principais interessados no ecossistema de negócios sem fio. Para desenvolver os modelos de negócios, usamos a tipologia de modelo de negócios na Internet em camadas $4 \mathrm{C}$ (Figura 1), (AGIWAL et al., 2019).

\section{Descrição detalhada da abordagem e dos resultados}

Cada um dos quatro cenários da Figura 3, compilado a partir dos 16 cenários originais, é descrito nos parágrafos a seguir. Os cenários criados representam futuros diferentes sobre como o contexto das redes $5 \mathrm{G}$ e serviços relacionados pode se desdobrar ao longo do tempo, considerando as mudanças regulatórias, oportunidades de negócios e inovações tecnológicas.

\section{Análise de cenário - Cenário 1: Eterno Hoje}

Apesar do aumento do tráfego nas redes móveis devido ao aumento do número de novos dispositivos com demandas de serviço aceleradas, que é plausível que seja o mesmo no futuro, o primeiro cenário pressupõe a continuação da situação atual (TRAN et al., 2017). Nesse cenário, espera-se que o ecossistema de negócios permaneça como hoje, sem novos participantes, principalmente devido ao pressuposto de que a estrutura regulatória não sofrerá alterações substanciais. As ofertas locais de serviços de pequenas células aumentarão, mas o papel central dos operadores multinacionais históricos de Operadoras de Rede Móvel (ORM) não mudará (PALATTELLA et al., 2016).

As ORM fornecem serviço de banda larga móvel agindo como canais de bits 'padrão' tradicionais que estendem suas ofertas a soluções tecnológicas verticais a segmentos específicos de clientes. Os serviços existentes se tornam fornecidos localmente, mas centralizados pelas ORM, no entanto, com algum nível de adaptação de serviço para as diferentes verticais. No que diz respeito à inovação tecnológica, os fabricantes de infraestrutura continuam empurrando novas tecnologias para os mercados (FREUND et al., 2019). 


\section{Cenário 2: Oeste Selvagem}

No segundo cenário, espera-se que a regulamentação seja flexível e a lógica tradicional de licenciamento de espectro a longo prazo será complementada com modelos locais de licenciamento de curto prazo (HINES et al., 2017). Da perspectiva do mercado, o 5 G nos leva a um portfólio de serviços amplamente utilizados, mas muito fragmentados, que se baseiam na localização da utilização de serviços e na centralização do fornecimento de serviços. No entanto, o ambiente de negócios se torna extremamente competitivo e as ameaças à segurança, confiabilidade e segurança surgem como um forte motivo de preocupação (DAl et al., 2015).

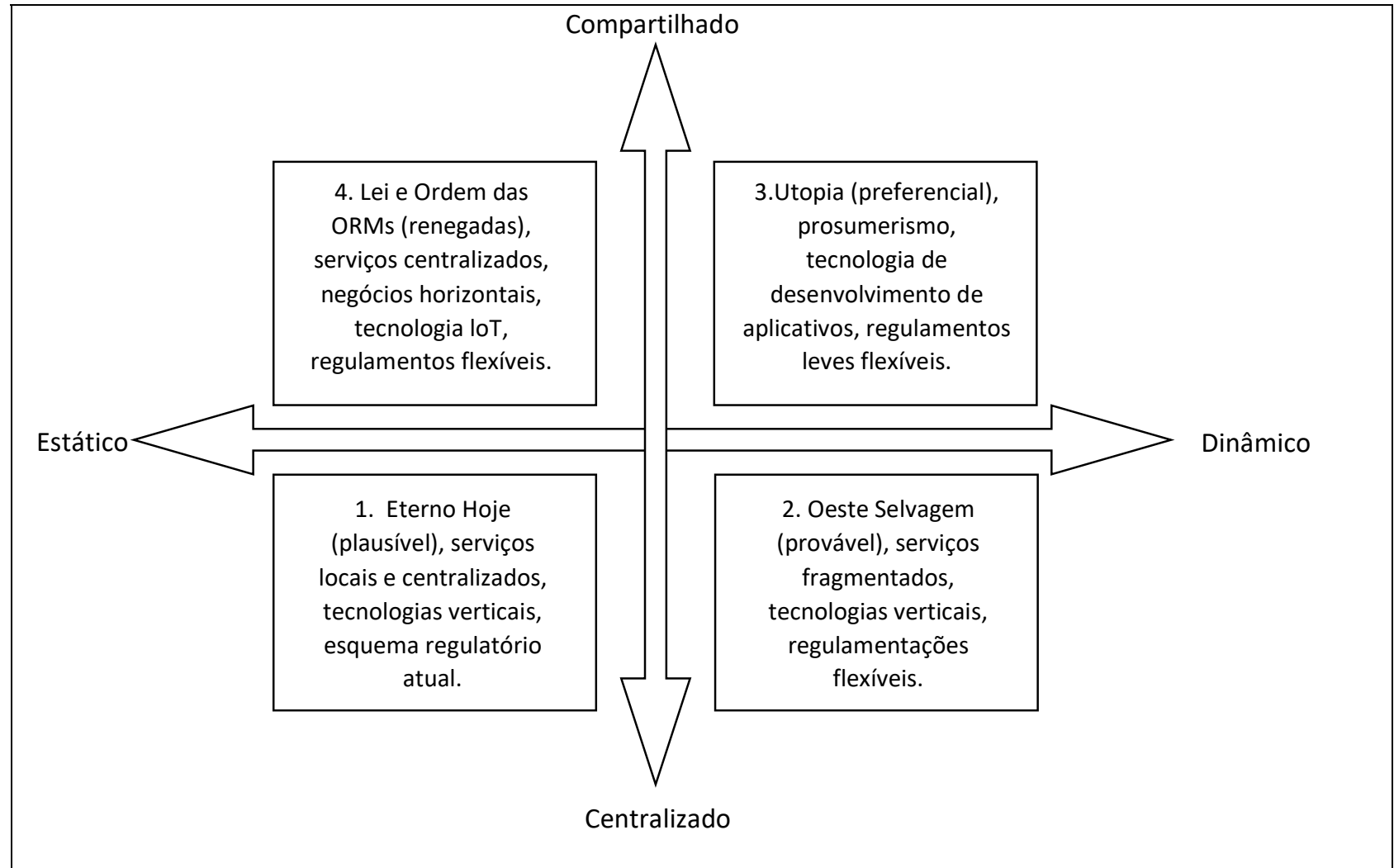

Figura 3: Matriz de cenário para redes $5 \mathrm{G}$.

Uma variedade de serviços específicos de conteúdo estará disponível e cada tipo de conteúdo possui seu modo específico de monetização. Inúmeros novos fornecedores de conectividade vertical surgirão nos mercados para competir entre si e contra as ORM tradicionais, e cada um deles prefere controlar (ou gerenciar) as informações e os serviços de seus clientes (GOKHBERG et al., 2016). O mercado de massa da banda larga móvel está fragmentado devido a uma ampla variedade de ofertas de serviços. Novos operadores locais (por exemplo, micro operadores) entram no mercado para atender a diferentes propósitos e necessidades tecnológicas que levam a um mercado de operadores fragmentado (DARKOW, 2015).

Devido à densidade de dados, são necessários sistemas inteligentes de controle de tráfego e canais de entrega personalizados. Nos setores industriais, as empresas verticais específicas locais usarão serviços digitais fornecidos por meio de redes de pequenas células. Novos casos de uso vertical, como serviços críticos de conectividade em hospitais, surgirão. Esse cenário é baseado nas tendências atuais reconhecidas e é provável que ocorra na era 5G (LEAL et al., 2016). 


\section{Cenário 3: Utopia}

O terceiro cenário descreve as características de um mercado móvel dinâmico em uma sociedade de economia compartilhada onde vários recursos são compartilhados. Presume-se que a regulamentação se torne apenas ligeiramente controlada e as partes interessadas do ecossistema possam agir facilmente dentro dos novos limites regulamentares simplificados (PIETROBELLI et al., 2016). As empresas dentro do ecossistema se tornarão centradas no serviço e os recursos necessários poderão ser obtidos em uma base compartilhada através da colaboração entre as partes interessadas do ecossistema. 0 provisionamento de conteúdo adaptado localmente surge e também pode ser distribuído para diferentes segmentos (TSUI, 2007).

O prosumerismo, onde os prestadores de serviços locais compram e vendem serviços, surgirá. Os serviços são principalmente baseados em conteúdo e diferentes infraestruturas e serviços relacionados são combinados para trabalharem juntos. Ter consciência do conteúdo e do contexto dos serviços locais requer uma atitude de compartilhamento (DAl et al., 2015).

\section{Cenário 4: Lei e ordem das ORM}

O quarto cenário é caracterizado por uma situação de mercado estática sem o aparecimento de novos participantes, mas os recursos necessários são compartilhados entre as partes interessadas. 0 regulamento promove o compartilhamento de vários recursos, como espectro e infraestrutura (DING et al., 2017). Esse cenário consiste em dois subcenários que descrevem o mesmo mundo das perspectivas centradas no dispositivo e no operador. O subcenário centrado no dispositivo e no conteúdo destaca o domínio dos gigantes da Internet que possuem e vendem conteúdo e os ORM atuam como canais de bits no mundo compartilhado (LEAL et al., 2016).

O ecossistema é orientado por dispositivos e conteúdo, onde os dispositivos móveis dos sistemas loT (Internet das Coisas) fornecem vários conteúdos. Como se supõe que o nível de compartilhamento de recursos seja alto nesse cenário, surgirão novos papéis das intermediárias de recursos, abrangendo o conhecimento de quando e a quem eles devem fornecer recursos, como espectro (CARPENTER, 2002).

No subcenário orientado pelo operador, as plataformas e interfaces dos ORM controlam os negócios/serviços horizontais e no 5G. Os ORM podem compartilhar recursos, mas apenas dentro da sua zona de conforto. Esse cenário é orientado para o cliente, pois a interoperação e as interfaces exigem mais serviços locais. Esses dois subcenários se assemelham ao futuro deserdado para as partes interessadas da pesquisa (PIETROBELLI et al., 2016).

\section{Modelagem de negócios}

Em um novo e complexo campo de negócios incerto, é prudente analisar o modelo de negócios existente desagregado (ou seja, decomposto). Isso é feito decompondo as posições existentes da cadeia de valor (por exemplo, operadora de rede) em suas funções na rede de valor (por exemplo, provedor de conexão e transferência de dados). Para propósitos da pesquisa, usou-se os blocos de construção da tipologia do 
modelo de negócios $4 \mathrm{C}$ e explorou-se que tipo de valor pode ser criado e capturado em cada uma das quatro camadas (ROHRBECK et al., 2018). Nesse modelo, o modelo de negócios de conectividade é sobre monetizar serviços de conectividade relacionados à infraestrutura de rede e provisionamento de espectro para troca de informações e usar serviços online de alta velocidade e necessidades relacionadas (por exemplo, banda larga móvel e comunicação M2M na loT) (GOKHBERG et al., 2016).

Tabela 3: Componentes de serviço desagrupados e seu elemento de modelo de negócios.

\begin{tabular}{|c|c|c|c|c|}
\hline $\begin{array}{l}\text { Elementos de } \\
\text { negócios }\end{array}$ & Conexão & Conteúdo & Concurso & Comércio \\
\hline $\begin{array}{l}\text { Proposta de } \\
\text { Valor }\end{array}$ & $\begin{array}{l}\text { - Facilidade de uso } \\
\text { - Mais tempo de conexão para } \\
\text { os usuários } \\
\text { - Porcentagem eficiente } \\
\text { - Comunicação como serviço } \\
\text { - Controle gráfico inteligente }\end{array}$ & $\begin{array}{l}\text { - A capacidade de } \\
\text { afastamento corresponde } \\
\text { à necessidade } \\
\text { - Dados do cliente e do } \\
\text { local } \\
\text { - QoS superior } \\
\text { - QoE sob medida } \\
\text { - Conteúdo local confiável } \\
\text { e rápido ou conteúdo } \\
\text { personalizado }\end{array}$ & $\begin{array}{l}\text { - Sensibilidade ao } \\
\text { contexto } \\
\text { - Perfil dos usuários }\end{array}$ & $\begin{array}{l}\text { - Entrega flexível } \\
\text { - Baixos custos de } \\
\text { transação } \\
\text { - Pague pelo que você } \\
\text { usa } \\
\text { - Conectividade de } \\
\text { baixo custo em } \\
\text { qualquer lugar }\end{array}$ \\
\hline Diferenciação & $\begin{array}{l}\text { - Experiência do usuário } \\
\text { - Aplicativos } \\
\text { - Serviços que outras pessoas } \\
\text { não possuem } \\
\text { - Otimizado a qualquer } \\
\text { momento e em qualquer lugar } \\
\text { (para o usuário final) } \\
\text { - Distribuição simplificada e } \\
\text { econômica (para fornecedores } \\
\text { de conteúdo) }\end{array}$ & $\begin{array}{l}\text { - Custo de investimento } \\
\text { compartilhado, incluindo } \\
\text { OPEX } \\
\text { - Extensões de rede para } \\
\text { ORM } \\
\text { - Uma cobertura interna } \\
\text { de 'rede' } \\
\text { - Base de clientes } \\
\text { conhecida para serviço } \\
5 G \\
\text { - Superioridade técnica } \\
\text { - Serviços locais } \\
\text { - Comunicação } \\
\text { - Personalização }\end{array}$ & $\begin{array}{l}\text { - Relevância do } \\
\text { serviço }\end{array}$ & $\begin{array}{l}\text { - Portfólio ilimitado } \\
\text { de serviços } \\
\text { - Comércio local vs. } \\
\text { Centralizado } \\
\text { - Baixo custo de } \\
\text { transação }\end{array}$ \\
\hline $\begin{array}{l}\text { Fatores de } \\
\text { custo }\end{array}$ & $\begin{array}{l}\text { - Controle/redução de OPEX } \\
\text { (despesas operacionais) } \\
\text { - Capacidade e cobertura }\end{array}$ & $\begin{array}{l}\text { - Dispositivo (sistemas } \\
\text { operacionais) } \\
\text { - Complexidade do } \\
\text { sistema e custo de } \\
\text { infraestrutura } \\
\text { - Custo do espectro } \\
\text { compartilhado } \\
\text { - Menos caixas } \\
\text { eletrônicos } \\
\text { - Menos publicidade } \\
\text { - Processos reduzidos }\end{array}$ & $\begin{array}{l}\text { - Agregação e } \\
\text { organização de } \\
\text { informações on-line } \\
\text { - Segurança dos } \\
\text { dados }\end{array}$ & $\begin{array}{l}\text { - Análise de big data } \\
\text { - Criação de perfil de } \\
\text { usuários } \\
\text { - Serviço em nuvem }\end{array}$ \\
\hline $\begin{array}{l}\text { Formas de } \\
\text { cobrança }\end{array}$ & $\begin{array}{l}\text { - Assinatura mensal (SIM, HW } \\
\text { + Serviços) } \\
\text { - Varia de acordo com o } \\
\text { cliente }\end{array}$ & $\begin{array}{l}\text { - Dispositivo } \\
\text { - Conta bônus } \\
\text { - Gratuito }\end{array}$ & $\begin{array}{l}\text { - Esquemas de bônus } \\
\text { - Faturamento B2B }\end{array}$ & $\begin{array}{l}\text { - Preço da licença } \\
\text { - Preço fixo } \\
\text { - Monetização } \\
\text { personalizada }\end{array}$ \\
\hline
\end{tabular}

O modelo de negócios orientado a conteúdo se baseia no fornecimento de todos os tipos de serviços relacionados a conteúdo online (áudio, vídeo, texto). Esse conteúdo pode ser de propriedade do provedor de serviços, de terceiros ou do usuário. O modelo de negócios relacionado ao contexto monetiza as informações estruturadas e agregadas relacionadas à rede, aplicativo, perfil do usuário, local, hora, dados históricos, equipamentos, sistemas operacionais e largura de banda necessária etc. (HINES et al., 2017). O modelo de negócio comercial baseia-se em uma plataforma para compra e vender recursos relacionados a conexão, conteúdo e contexto, ou qualquer combinação deles. Diferentes tipos de comunicação, incluindo 
negócios (B), consumidor (C) e público/governo (G), podem ser identificados e monetizados nessa camada (veja a Figura 1).

A estrutura 4C orienta o raciocínio indutivo dos participantes do workshop. No workshop, os participantes especificaram colaborativamente os componentes de serviço para os elementos do modelo de negócios desagregados (LEAL et al., 2016). Os elementos do modelo de negócios listados na Tabela 3, incluindo proposição de valor, diferenciação, direcionadores de custos e formas de cobrança, estão relacionados à criação de valor das partes interessadas e capturam oportunidades por meio de componentes de serviço na estrutura 4C (ROHRBECK et al., 2018).

Nesta etapa, evita-se propositadamente combinar os elementos do modelo de negócios com sua função na rede de valor, para garantir que os participantes não sejam afetados por vieses. Em particular, é necessário evitar que os participantes comecem a se concentrar em proteger sua posição atual na rede de valor e, consequentemente, reduzir as opções que estão sendo discutidas. Na próxima etapa, reinduziu-se a incerteza ao trazer os quatro cenários de volta ao processo. Embora os cenários sejam vitais para impedir que os participantes caiam mentalmente em representações e modelos mentais estabelecidos, precisa-se nesta etapa também para impulsionar a convergência dos insights de exploração de mercado. A lógica é que a convergência é necessária para estabelecer as bases da ação, mas que precisa ser alcançada de uma maneira que não comprometa o processo aberto de exploração de novas configurações de negócios e de mercado.

Conseguiu-se isso identificando elementos do modelo de negócios adequados para serem aplicados em um determinado cenário. Esse processo se assemelha ao raciocínio analógico através do qual a criação/mapeamento de conhecimento (por exemplo, padrões distintivos) de um domínio familiar para um domínio novo ou menos familiar ocorre. Isso leva ao estabelecimento de opções e à formação de um novo ambiente relacional (DAl et al., 2015). Dessa forma, a atenção dos estrategistas é focada na tarefa cognitiva de encontrar um modelo de negócios ideal em um determinado ambiente e, portanto, distraída de proteger, por exemplo, sua própria posição competitiva no mercado. Esse tipo de mapeamento cognitivo (isto é, analogia) faz com que os tomadores de decisão estejam mais conscientes de sua crença subjetiva própria e alheia, portanto, altera/facilita o processo de tomada de decisão (DING et al., 2017). Os resultados desta atividade estão representados na Tabela 4.

Os principais insights são que, no cenário Eterno Hoje, orientado para a tecnologia, as ORM têm um papel dominante e espera-se que os fornecedores de infraestrutura de rede e de dispositivos complementem o ecossistema. Modelos de negócios de conectividade (banda larga móvel), contexto (densidade de dados e usuários monetizados) e comércio (com esquemas de anúncios ou bônus) podem fornecer a maior parte do novo valor agregado no ecossistema (LEAL et al., 2016).

O cenário do Oeste Selvagem é mais orientado a serviços e mostrou o surgimento de micro operadoras como novos atores-chave no fornecimento de banda larga móvel como serviço local. Os modelos de negócios dominantes monetizam a conexão móvel localmente (por micro operadoras) e soluções tecnológicas personalizadas e serviços de conteúdo verticais (ROHRBECK et al., 2018). Ao comparar com o 
cenário Eterno Hoje, o papel dos proprietários do conteúdo, dos agregadores de conteúdo, dos provedores de aplicativos e dos micros operadores é mais pronunciado (DING et al., 2017).

Tabela 4: A visão geral dos cenários e suas camadas 4C.

\begin{tabular}{|c|c|c|c|c|c|}
\hline & \multicolumn{5}{|c|}{ Ecossistema $5 \mathrm{G}$} \\
\hline Cenário de 4C & Conexão & Conteúdo & Contexto & Comércio & $\begin{array}{l}\text { Fatores chave de } \\
\text { cada cenário }\end{array}$ \\
\hline $\begin{array}{l}\text { Cenário 1: ORM } \\
\text { orientados para a } \\
\text { tecnologia Eterno } \\
\text { Hoje dominam }\end{array}$ & $\begin{array}{l}\text { - Banda larga móvel como } \\
\text { oferecida hoje }\end{array}$ & & $\begin{array}{l}\text { - Densidade de } \\
\text { dados e usos } \\
\text { monetizada }\end{array}$ & $\begin{array}{l}\text { - Baseado } \\
\text { em } \\
\text { assinatura } \\
\text { - Anúncios } \\
\text { - Bônus }\end{array}$ & $\begin{array}{l}\text { - Fabricantes de } \\
\text { dispositivos } \\
\text { - Equipamentos de } \\
\text { rede } \\
\text { - Proprietários de } \\
\text { espectro e } \\
\text { infraestrutura }\end{array}$ \\
\hline $\begin{array}{l}\text { Cenário 2: Micro } \\
\text { operadores } \\
\text { orientados a } \\
\text { serviços do Oeste } \\
\text { Selvagem } \\
\text { dominantes }\end{array}$ & $\begin{array}{l}\text { - Permitir a oferta de } \\
\text { banda larga móvel em } \\
\text { mercados/ambientes } \\
\text { fragmentados }\end{array}$ & $\begin{array}{l}\text { - Soluções } \\
\text { tecnológicas } \\
\text { verticais } \\
\text { - Serviços } \\
\text { personalizados }\end{array}$ & & & $\begin{array}{l}\text { - Proprietários e } \\
\text { agregadores de } \\
\text { conteúdo } \\
\text { - Provedores de } \\
\text { aplicativos } \\
\text { - Integradores de } \\
\text { sistemas }\end{array}$ \\
\hline $\begin{array}{l}\text { Cenário 3: Utopia } \\
\text { Serviço e } \\
\text { tecnologia } \\
\text { Operadores } \\
\text { dominantes }\end{array}$ & $\begin{array}{l}\text { - Garantir a oferta de } \\
\text { banda larga móvel através } \\
\text { do compartilhamento }\end{array}$ & $\begin{array}{l}\text { - Vários } \\
\text { aplicativos } \\
\text { - Serviços de } \\
\text { conteúdo local }\end{array}$ & $\begin{array}{l}\text { - Criação de } \\
\text { perfil de } \\
\text { usuários } \\
\text { - Serviço de } \\
\text { conteúdo } \\
\text { definido por } \\
\text { contexto }\end{array}$ & & $\begin{array}{l}\text { - Combinação dos } \\
\text { atores dos cenários } 1 \\
\text { e } 2 \text {, ou seja, } \\
\text { prestadores de } \\
\text { serviços profissionais }\end{array}$ \\
\hline $\begin{array}{l}\text { Cenário 4: Lei e } \\
\text { Ordem das ORMs } \\
\text { reguladoras e } \\
\text { orientadas a } \\
\text { serviços dominam }\end{array}$ & $\begin{array}{l}\text { - Cobertura total (por } \\
\text { ORM) através do } \\
\text { provisionamento de } \\
\text { espectro }\end{array}$ & $\begin{array}{l}\text { - Dispositivos } \\
\text { loT } \\
\text { - QoS superior } \\
\text { - serviços } \\
\text { específicos do } \\
\text { cliente }\end{array}$ & & $\begin{array}{l}\text { - Preços } \\
\text { das licenças } \\
\text { - Sucção } \\
\text { do espectro } \\
\text { - B2B } \\
\text { baseado } \\
\text { em nuvem }\end{array}$ & $\begin{array}{l}\text { - Governo, } \\
\text { autoridades } \\
\text { reguladoras e grupos } \\
\text { de padronização }\end{array}$ \\
\hline & Criação e captura de valor & ecífico 5G & & & \\
\hline
\end{tabular}

O cenário da Utopia é orientado a serviços e tecnologia. É dominado por micro operadores emergentes que criam e capturam valor por meio da conectividade, conteúdo e contexto, mas dependem dos recursos das ORM (HINES et al., 2017). Uma variedade de micro operadoras fornece serviços profissionalmente para todos os tipos de clientes localmente (ou seja, em verticais selecionadas) e as ORM fornecem ao micro operadoras a conectividade necessária a outras redes e à Internet. Além disso, os serviços de conteúdo definido pelo contexto para usuários com perfil, ou conteúdo local, fornecem a principal vantagem competitiva. Além disso, o compartilhamento da infraestrutura desempenha um papel importante nesse cenário (DAl et al., 2015).

O cenário de Lei e Ordem das ORM é orientado a serviços e regulamentos; é dominado por ORM. Modelos de negócios de conexão, conteúdo e comércio são as principais maneiras de fazer negócios (DARKOW, 2015). Nesse cenário, a futura política regulatória do 5G preocupa-se em melhorar a eficiência do uso do espectro, em vez de abrir o mercado a um conjunto mais versátil de participantes por meio de direitos locais de acesso ao espectro para aumentar a concorrência (HINES et al., 2017).

Como não se espera que novos players do mercado surjam, pode-se esperar que o mercado de serviços local seja dividido entre dispositivo/conteúdo e fragmentos de ORM/conectividade. No geral, o 
exercício de planejamento de cenários e modelos de negócios destacou o papel principal da regulamentação, que deve ser flexível nos três últimos cenários em que o terceiro cenário é mais distante, assumindo a abertura do mercado para operações dinâmicas e o compartilhamento de vários recursos (ROHRBECK et al., 2018). O segundo fator-chave é o fornecimento de serviços, que reflete se é ideal avançar para o compartilhamento e atividades dinâmicas entre os operadores e se esse compartilhamento ocorre entre ORM ou entre operadores locais. A tecnologia é um driver substancial de todos os cenários, mas sua importância não varia entre os cenários (HINES et al., 2017).

\section{CONCLUSÕES}

Tecnologias inovadoras como o $5 \mathrm{G}$ exigirão novos modelos de negócios para a implantação de recursos e capacidades; capacidade de ajustar estrategicamente os recursos às demandas e criar oportunidades de proposição de valor em um rico ecossistema de provedores de serviços. Além disso, é crucial ser ágil e resiliente à incerteza e complexidade ambientais (FREUND et al., 2019). Os modelos de negócios demonstram os modelos e esquemas mentais dos gerentes e são uma conceituação abstrata que diz respeito à criação de sentido e podem mapear e facilitar as mudanças possíveis ou necessárias com base nas novas condições que levam à inovação. E vantagem competitiva (DING et al., 2017).

Com este artigo, busca-se contribuir para uma melhor compreensão e, finalmente, uma melhor execução no desenvolvimento de novos mercados em ambientes caracterizados por altos níveis de volatilidade, incerteza, complexidade e ambiguidade conhecidos como VUCA. Entrar em ambientes como uma empresa mantém a promessa de lucratividade e crescimento superiores. É necessário entrar em ambientes como as sociedades para superar grandes desafios, como mudanças climáticas, escassez de água e recursos naturais limitados. Cumprir a promessa de lucratividade e crescimento superiores e responder com sucesso aos desafios da sociedade exige superar a racionalidade limitada (ROHRBECK et al., 2018).

A capacidade dos gerentes é limitada em antecipar e responder a mudanças no ambiente; eles são incapazes de repensar antes que a mudança estratégica aconteça e percebam o ambiente de uma maneira nova e diferente (HINES et al., 2017). Resolver isso exige que os tomadores de decisão, aos quais também nos referimos como estrategistas, identifiquem cursos superiores de ação alterando modelos mentais, criando novas representações compartilhadas e poderosas (TSUI, 2007).

Espera-se que isso pudesse ser apoiado por métodos e abordagens de previsão estratégica (LEAL et al., 2016), como o planejamento de cenários que permita reduzir a distância cognitiva que pode ser a consequência da falta de conhecimento prévio; revisando o pressuposto anterior dado como garantido, aprofundando a conscientização e aprimorando a atenção ao ambiente dinâmico e a escolhas alternativas (DING et al., 2017).

As premissas revisadas e a antecipação atualizada são comparáveis ao ajuste dos scripts cognitivos, ou seja, a cadeia lógica e consistente de ações esperadas pelos indivíduos. É crucialmente importante saber como os eventos que parecem significativos para nós devem ser selecionados e reunidos à medida que se desenrolam ao longo do tempo (MAHONEY et al., 1992). Nesta pesquisa, abordamos essa importância 
projetando e testando uma nova abordagem que combina o planejamento de cenários com a modelagem de negócios (ou seja, pense estrategicamente nos cenários e atue estrategicamente nos modelos de negócios) para a exploração colaborativa de um mercado futuro significativamente alterado por uma interrupção tecnológica (TSUI, 2007).

Aplicou-se nossa nova abordagem no contexto do mercado de telefonia móvel, que enfrentará uma transição importante quando os padrões da 5a geração estiverem sendo introduzidos. Conclui-se que, mesmo trabalhando com participantes do mercado, conseguimos criar representações significativamente diferentes do status quo (os cenários). Além disso, descobrimos que essas representações eram poderosas e tangíveis o suficiente para funcionar como uma plataforma para definir modelos de negócios.

Utilizando a dinâmica do processo e formando grupos de trabalho compostos por participantes de diferentes lugares da rede de valores, conseguimos impedir que os participantes caíssem em padrões cognitivos estabelecidos. Para entender melhor as combinações de métodos adequadas em diferentes ambientes, são necessários mais estudos que apliquem abordagens combinadas em diferentes contextos. Além disso, seria benéfico controlar os vieses cognitivos e como as abordagens contribuem para sua redução.

Ao induzir a pluralidade através dos cenários, permitiu desencadear e sediar uma criação estratégica de sentidos que superou os modelos mentais estabelecidos e levou a representações prospectivas e compartilhadas entre os participantes (CARPENTER, 2002). Chega-se à conclusão de que nossa abordagem contribuiu para evitar a cegueira e facilitar o aprendizado com a retrospecção (TSUI, 2007). Contar histórias e desenvolver teorias aprimoram as interações dos participantes enquanto eles compartilham sua percepção do ambiente.

As histórias que os indivíduos contam sobre o futuro ilustram as visões de mundo dos indivíduos e essa narração resulta na descoberta de histórias (ou seja, modelos mentais) que são adaptadas às necessidades específicas e aceleram o futuro desejado. Ele desconstrói e reconstrói o entendimento da incerteza e do risco e desafia as premissas subjacentes e, em última análise, preenche a lacuna entre o futuro desejado e as realidades existentes (PIETROBELLI et al., 2016). Esse processo aumenta a criatividade e a capacidade intelectual dos participantes. $O$ aprendizado ocorre enquanto os participantes moldam e definem o futuro de forma iterativa, considerando que seriam afetados pelas consequências do futuro que estão imaginando (DING et al., 2017). Por fim, documenta-se que a abordagem levou ao surgimento de dois tipos de resultados: primeiro, a criação de caminhos alternativos para múltiplos futuros plausíveis e, segundo, a integração de métodos de previsão orientados à exploração, como o planejamento de cenários com técnicas de modelagem de negócios orientadas ao planejamento, estão aumentando a percepção e a probabilidade de ação significativa.

O planejamento de cenários e a modelagem de negócios estão envolvidos no mapeamento, ou seja, na detecção de fatores determinantes e na visualização de possibilidades alternativas e envolvem processos cognitivos, colaborativos e coletivos para criar e desenvolver conhecimento com o objetivo de criar estratégias e planejar. Espera-se que essas combinações personalizadas de métodos tenham um papel cada vez mais importante na exploração colaborativa do mercado, criando valor tanto no nível da empresa quanto 
na sociedade.

\section{REFERÊNCIAS}

AGIWAL, M.; SAXENA, N.; ROY, A.. Towards connected living: $5 \mathrm{~g}$ enabled internet of things (iot). IETE Technical Review, v.36, n.2, p.190-202, 2019.

BEGA, D.; GRAMAGLIA, M.; BANCHS, A.; SCIANCALEPORE, V.; COSTA-PEREZ, X.. A machine learning approach to $5 G$ infrastructure market optimization. IEEE Transactions on Mobile Computing, n.99, p.1-1, 2019.

CARPENTER, M. A.. The implications of strategy and social context for the relationship between top management team heterogeneity and firm performance. Strategic Management Journal, v.23, n.3, p.275-284, 2002.

DAI, L.; WANG, B.; YUAN, Y.; HAN, S.; CHIH-LIN, I.; WANG, Z.. Non-orthogonal multiple access for 5G: solutions, challenges, opportunities, and future research trends. IEEE Communications Magazine, v.53, n.9, p.74-81, 2015.

DING, Z.; LEI, X.; KARAGIANNIDIS, G. K.; SCHOBER, R.; YUAN, J.; BHARGAVA, V. K.. A survey on non-orthogonal multiple access for $5 G$ networks: Research challenges and future trends. IEEE Journal on Selected Areas in Communications, v.35, n.10, p.2181-2195, 2017.

DARKOW, I. L.. The involvement of middle management in strategy development: Development and implementation of a foresight-based approach. Technological Forecasting and Social Change, v.101, p.10-24, 2015.

DOKTOR, R.; TUNG, R. L.; GLINOW, M. A. V.. Incorporating international dimensions in management theory building. Academy of Management Review, v.16, n.2, p.259261, 1991.

FREUND, R.; HAUSTEIN, T.; KASPARICK, M.; MAHLER, K.; SCHULZ-ZANDER, J.; THIELE, L.; WEILER, R.. 5G Data Transfer at Maximum Speed. In: FREUND, R.; HAUSTEIN, T.; KASPARICK, M.; MAHLER, K.; SCHULZ-ZANDER, J.; THIELE, L.; WEILER, R.. Digital Transformation. Heidelberg: Springer Vieweg, 2019. p.87-107.

GOKHBERG, L.; MEISSNER, D.; SOKOLOV, A.. Foresight: turning challenges into opportunities. In: Deploying Foresight for Policy and Strategy Makers. Cham: Springer, 2016. p.1-8
HINES, A.; GARY, J.; DAHEIM, C.; VAN DER LAAN, L.. Building foresight capacity: toward a foresight competency model. World Futures Review, v.9, n.3, p.123-141, 2017.

JAUCH, L. R.; KRAFT, K. L.. Strategic management of uncertainty. Academy of Management Review, v.11, n.4, p.777-790, 1986.

LEAL, C.; MARQUES, C. P.; MARQUES, C. S.; RATTEN, V.. The role of intellectual capital and corporate strategy on sustainable value creation. International Journal of Foresight and Innovation Policy, v.11, n.4, p.215-224, 2016.

MAHONEY, J. T.; PANDIAN, J. R.. The resource-based view within the conversation of strategic management. Strategic Management Journal, v.13, n.5, p.363-380, 1992.

PALATTELLA, M. R.; DOHLER, M.; GRIECO, A.; RIZZO, G.; TORSNER, J.; ENGEL, T.; LADID, L.. Internet of things in the 5G era: Enablers, architecture, and business models. IEEE Journal on Selected Areas in Communications, v.34, n.3, p.510-527, 2016.

PIETROBELLI, C.; PUPPATO, F.. Technology foresight and industrial strategy. Technological Forecasting and Social Change, v.110, p.117-125, 2016.

ROHRBECK, R.; KUM, M. E.. Corporate foresight and its impact on firm performance: A longitudinal analysis. Technological Forecasting and Social Change, v.129, p.105-116, 2018.

TRAN, T. X.; HAJISAMI, A.; PANDEY, P.; POMPILI, D.

Collaborative mobile edge computing in $5 \mathrm{G}$ networks: New paradigms, scenarios, and challenges. IEEE Communications Magazine, v.55, n.4, p.54-61, 2017.

TSUI, A. S.. From homogenization to pluralism: International management research in the academy and beyond. Academy of Management Journal, v.50, n.6, p.1353-1364, 2007.

VENKATRAMAN, N.; CAMILLUS, J. C.. Exploring the concept of ' $\mathrm{fit}$ ' in strategic management. Academy of Management Review, v.9, n.3, p.513-525, 1984.

A CBPC - Companhia Brasileira de Produção Científica (CNPJ: 11.221.422/0001-03) detém os direitos materiais desta publicação. Os direitos referem-se à publicação do trabalho em qualquer parte do mundo, incluindo os direitos às renovações, expansões e disseminaç̃̃es da contribuição, bem como outros direitos subsidiários. Todos os trabalhos publicados eletronicamente poderão posteriormente ser publicados em coletâneas impressas sob coordenação da Sustenere Publishing, da Companhia Brasileira de Produção Científica e seus parceiros autorizados. Os (as) autores (as) preservam os direitos autorais, mas não têm permissão para a publicação da contribuição em outro meio, impresso ou digital, em português ou em tradução. 